\title{
Charles J. Epstein, Robert P. Erickson, Anthony Wynshaw-Boris (eds): Inborn errors of development
}

\author{
2nd edn, OUP, 2008, HB, 1617 pages, £160, ISBN 139780195306910, ISBN 100195306910
}

\author{
John Tolmie
}

Published online: 29 January 2009

(C) Springer-Verlag 2009

The first edition of this book, published in 2004, was roundly praised. From the Association of American Publishers it received the accolade, 'Best Medical Book of the Year'. In the journal, Developmental Biology, it was hailed a masterpiece. It reached 869,417 in the Amazon Sales Rank. Nevertheless, the editors and authors have not rested upon their laurels and 4 years later a much expanded, rewritten and updated second edition has been published.

In over 180 chapters written by twice as many authors, there are details of signalling pathways, gene families, genetic processes and gene malfunctions that give rise to a multitude of malformation and dysmorphic syndromes. At the beginning, general introductory chapters synthesise medical embryology with molecular principles of differentiation and morphogenesis. Thus, if you too graduated decades ago and have less than working knowledge of ligands, receptors, kinases and transcription factors, this section contains all the science necessary to dispel most, but by no means all, of the mystery of differentiation. These early chapters, written as they are by world experts, are supremely informative on development of organs and systems, but they also emphasise fundamental concepts, such as homeostasis and redundancy, as a prelude to what happens when things go wrong.

The bulk of the book covers a selection of common, less common and some very rare syndromes where there is knowledge of developmental pathogenesis. Although some favourite syndromes are absent and some important terms, such as microcephaly, have still to appear in the index, the reader may be confident that omissions will be sorted because increasing knowledge of developmental pathogenesis is an absolutely rock solid guarantor for future editions.

Concerning the future, although speculation is generally frowned upon in science and medicine, it is permissable in a book review. After the first edition of Inborn Errors was published, it was predicted that the second edition might have 'a pullout wall chart linking all the known molecular developmental cascades in the sort of multidirectional interrelated nightmarish diagram that is much beloved of biochemists'. Alas no, at least not yet. But the second edition does come with a companion web site that intends to present a variety of additional material as well as update the text. At the time of writing, most material on this site comprises supplementary references. In the future, I hope there will be many more online illustrations, and it would be very nice if a proportion is in the 'teaching slide' format that has become popular, and also constitutes an attractive advert for the source.

In summary, this text has not achieved its 'classic' status by any simple measure of depth, breadth or verbosity. Rather the editors and authors have excelled in communicating mind-bogglingly complex processes to a very wide readership who may now marvel and consider how lucky we are to be studying, researching or otherwise employed at such a moment in time.

J. Tolmie $(\bowtie)$

Yorkhill Hospitals, Glasgow G3 8SJ, UK

e-mail: john.tolmie@nhs.net 